\title{
Video Pembelajaran untuk Generasi New Milenial
}

\author{
Hana Sih Setya Rahayu ${ }^{a}$, Endang Wara Suprihatin Dyah Pratamawati ${ }^{\mathrm{b}}$, \\ Rully Aprilia Zandra ${ }^{c}$ \\ Jurusan Seni dan Desain, Fakultas Sastra, Universitas Negeri Malang, \\ Corresponding email: rullyzandra.fs@um.ac.id
}

\begin{abstract}
Abstrak: Video merupakan bagian kehidupan yang tidak bisa dielakkan lagi pada siswa generasi new milenial. Namun, tidak semua video pembelajaran tari menarik untuk dicermati hingga akhir bagi siswa usia SMP. Untuk menjembatani gap ini, penelitian difokuskan pada pengembangan video pembelajaran tari yang baik untuk mendukung pembelajaran tari pada siswa SMP. Data dikumpulkan dengan cara melakukan observasi dan wawancara pada siswa, meminta masukan teknis pada validator, dan menguji cobakan produk pada siswa. Analisis dilakukan dengan mengkonfirmasi produk awal pada masukan validator, mengkonfirmasi produk kedua dan ketiga pada rekomendasi uji coba sample, dan mengkonfirmasi sekali lagi produk akhir pada validator. Hasil penelitian ini menunjukkan bahwa baik dari responden, validator, dan pengguna pada uji coba membutuhkan video yang memiliki point of interest pada introduksi di menit pertama dan penggalan highlight tarian di menit kedua. Sehingga, dapat disimpulkan bahwa video pembelajaran tari yang baik adalah video yang membangun rasa penasaran penontonnya pada 2 menit pertama.
\end{abstract}

Kata Kunci: video pembelajaran, penelitian pengembangan, siswa new milenial

Abstract: Video is an inevitable part of life for new millennial generation students. But, not all dance learning videos are interesting to watch until the end for student's of junior high school. To this gap, research is focused on developing good dance learning videos to support dance learning for student's of junior high school. Data is collected by conducting observations and interviews with students, asking for technical input to the validator, and testing the products on students. Analysis is done by confirming the initial product at the validator input, confirming the initial product at the trial sample recommendation, and confirming once again the final product at the validator. The result of this research indicate that both respondents, validators, and user in trials need videos that have a point of interest in the introduction in the first minute and fragments of dance highlights in the second minute. So, it can be concluded that a good dance learning video is a video that builds the curiosity of the audience in the first 2 minutes.

Keywords: $\quad$ learning videos, development research, millennial generation students

(C2020 -Ini adalah artikel dengan akses terbuka dibawah licenci CC BY-NC-4.0

(https://creativecommons.org/licenses/by-nc/4.0/) by penulis. 


\section{PENDAHULUAN}

Teknologi sangat berperan dalam dunia pendidikan sesuai dengan perkembangan zaman (Rahmawati, Pratamawati, \& Zandra, 2017). Teknologi pendidikan sangat erat hubungannya dengan proses belajar mengajar yang dilakukan oleh guru dan siswa (Rahayuningtyas, 2013), bertujuan untuk ikut serta mencerdaskan dan membantu dalam hal mencapai tujuan pembelajaran (Rahmawati et al., 2017).

Teknologi Pembelajaran merupakan salah satu bidang yang berupaya membantu proses belajar dengan memanfaatkan secara optimal komponen-komponen pembelajaran melalui fungsi pengembangan dan pengelolaan (Khusairi, Zandra, \& Harini, 2019).

Uraian tersebut membuktikan bahwa teknologi sangat berperan dalam dunia pendidikan (Khusairi et al., 2019). Peran media dalam pembelajaran juga penting, yakni sangat memengaruhi penerimaan materi oleh siswa.

Pengembangan media pembelajaran dirasa sangat perlu untuk kemajuan dunia pendidikan. Suatu proses belajar mengajar, dua unsur yang amat penting adalah metode mengajar dan media pembelajaran(Arsyad, 2014).

Siswa dalam memahami materi pembelajaran memiliki cara yang berbeda-beda. Media pembelajaran yang baik diharapkan mampu membangkitkan minat dan motivasi siswa baik berupa metode maupun pendekatan melalui alat bantu media dengan berlandaskan fase kegiatan membelajarkan (Rahayuningtyas, 2013).

Bentuk media pembelajaran bermacammacam, antara lain berupa buku paket, modul, buku pop up, video, dan lain sebagainya. Video berasal dari bahasa Latin, video-vidi-visum yang artinya melihat (mempunyai daya penglihatan); dapat melihat. Arsyad (Arsyad, 2014) menyatakan bahwa video merupakan gambargambar dalam frame, frame demi frame diproyeksikan melalui lensa proyektor secara mekanis sehingga pada layar terlihat gambar itu hidup. Video memiliki berbagai peran(Sasmito \& Rahayu, 2014), selain sebagai sarana hiburan, video juga dapat berfungsi sebagai media pembelajaran(Rahmawati et al., 2017). Media pembelajaran berupa video dapat membantu siswa dalam belajar karena siswa tertarik untuk memperhatikan tayangan video dan mendengarkan audio(R A Zandra, Wido, \& Desta, 2018)(Rully Aprilia Zandra, 2014).
Gadget merupakan alat komunikasi dan hiburan yang pasti dimiliki dan digunakan oleh banyak orang(Rully Aprilia Zandra, 2019). Penggunaan aplikasi baik secara online maupun offline dapat menayangkan video pembelajaran apapun. Kemudahan mengakses video membuat setiap orang terutama siswa sangat mudah untuk menerima pembelajaran. Saat ini, video merupakan bagian kehidupan yang tidak bisa dielakkan lagi pada setiap aspek kehidupan. Siswa seringkali menggunakan video sebagai alat bantu untuk belajar.

Banyak sekali orang yang membuat media pembelajaran berupa video. Namun pesatnya perkembangan teknologi, viewer akan lebih pandai untuk memilih dan melihat video dibutuhkan dan yang disukai. Siswa seringkali bosan terhadap tayangan video pembelajaran yang ditontonnya (wawancara oleh Ronald), siswa merasa video pembelajaran yang ditayangkan hanya itu-itu saja (wawancara oleh Adelia), siswa merasa video pembelajaran yang ditayangkan sudah sering dilihat (wawancara oleh Alisha), siswa merasa video pembelajaran yang ditayangkan membuat mengantuk (wawancara oleh Romi). Sehingga, tidak semua video pembelajaran tari menarik untuk dicermati dari awal hingga akhir bagi siswa SMP.

Untuk menjembatani gap ini, penelitian difokuskan pada pengembangan video pembelajaran tari yang baik untuk mendukung pembelajaran tari pada siswa SMP.

\section{METODE}

Teknik pengumpulan data dalam penelitian ini menggunakan beberapa metode sebagai berikut:

\subsection{Observasi}

Teknik pengumpulan data yang pertama ialah observasi, secara pasif penulis ikut terlibat dalam kegiatan pembelajaran (R A Zandra et al., 2018). Observasi dilakukan untuk mengetahui apa saja yang dibutuhkan dalam suatu kegiatan pembelajaran agar siswa dapat menerima dan memahami materi pembelajaran dengan baik.

\subsection{Wawancara}

Penelitian ini menggunakan wawancara tak berstruktur dan secara terus terang/terbuka (R A Zandra et al., 2018), peneliti mengajukan pertanyaan kepada narasumber secara leluasa sehingga diperoleh informasi yang lebih akurat. Wawancara terbuka adalah wawancara kepada narasumber dan mereka tahu bahwa mereka sedang diwawancarai dan tahu tujuan 
wawancara itu untuk apa. Wawancara terbuka dilakukan peneliti kepada siswa, guru, validator, dan narasumber tarian. Adapun para tokoh dan subjek yang menjadi narasumber adalah:

a. Adelia Vellysa, siswa kelas VIII C SMP Negeri 1 Tumpang.

b. Alisha, siswa kelas VIII C SMP Negeri 1 Tumpang.

c. Romi, siswa kelas VIII C SMP Negeri 1 Tumpang.

d. Ronald Matik, guru Seni Budaya kelas VIII C SMP Negeri 1 Tumpang.

e. Robby Hidajat, dosen jurusan Seni dan Desain Universitas Negeri Malang.

f. Andhika Putra Herwanto, dosen jurusan Seni dan Desain Universitas Negeri Malang.

\subsection{Dokumentasi}

Dokumentasi adalah foto saat wawancara dan proses pembelajaran, rekaman audio, dan video yang digunakan dalam penelitian sebagai sumber data (R A Zandra et al., 2018) dan dapat dimanfaatkan untuk mengkaji dan menafsirkan.

Instrumen pengumpulan data yang digunakan dalam penelitian dan pengembangan ini berupa angket. Angket merupakan teknik pengumpulan data yang dilakukan dengan cara memberikan seperangkat pertanyaan atau pernyataan tertulis kepada responden untuk dijawabnya (Sugiyono, 2015).

Angket berisikan tentang pertanyaan dan kriteria penilaian untuk media pengembangan ini (Sugiyono, 2015). Responden hanya memilih jawaban yang telah disediakan. Wawancara dilakukan kepada siswa, guru, narasumber tari, dosen sebagai validator materi dan media.

Data dikumpulkan dengan cara melakukan observasi dan wawancara pada siswa, meminta masukan teknis pada validator, dan menguji cobakan produk pada siswa. Analisis dilakukan dengan mengkonfirmasi produk awal pada masukan validator, mengkonfirmasi produk kedua dan ketiga pada rekomendasi uji coba sample, dan mengkonfirmasi sekali lagi produk akhir pada validator.

\section{HASIL DAN PEMBAHASAN}

Pada pendahuluan telah disinggung bahwa media pembelajaran yang baik diharapkan mampu membangkitkan minat dan motivasi siswa baik berupa metode maupun pendekatan melalui alat bantu media dengan berlandaskan fase kegiatan membelajarkan.

Analisis data hasil validasi ahli diberikan penilaian secara langsung validator materi dan validator media, uji coba kelompok kecil dan uji coba kelompok besar oleh siswa SMP.

Pada penelitian ini, media pembelajaran berbasis video berisi tentang sinopsis tari, unsurunsur pendukung tari, karakteristik kostum tari, cara pemakaian kostum, tarian full. Video ini memiliki durasi 15 menit. Video pembelajaran ini dibuat oleh peneliti dengan bantuan videographer dan editor. Setelah produk video selesai, peneliti mengkonsultasikan kepada narasumber tari tentang materi tari. Kemudian, peneliti meminta saran kepada validator media tentang spesifikasi video tersebut. Peneliti juga meminta saran kepada validator materi tentang kesesuaian materi pada video dengan kompetensi dasar yang sedang dipelajari oleh siswa SMP.

Para ahli diminta untuk mengisi angket yang telah diberikan oleh peneliti. Angket tersebut berisi tentang materi yang sesuai dengan keahlian para validator dn narasumber tari.

Angket yang diberikan pada narasumber berisi tentang kesesuaian materi tarian. Angket yang diberikan kepada validator materi berisi tentang kesesuaian materi pembelajaran dengan tarian serta kesesuaian penerimaan untuk siswa SMP. Sedangkan angket yang diberikan kepada validator media berisi tentang spesifikasi tayangan pada video pembelajaran tersebut.

Masukan dari narasumber ialah kesesuaian gerak penari dengan musik. Masukan dari validator media ialah kurangnya pencahayaan pada video tersebut saat menarikan tarian secara penuh, adanya missfocus pada ECU. Masukan dari validator materi ialah perlu menambahkan materi pengertian unsur-unsur pendukung tari tradisi serta penambahan karakteristik kostum pada tari.

Setelah adanya masukan oleh para ahli, peneliti kemudian merevisi media pembelajaran dengan bantuan editor. Setelah media pembelajaran tersebut selesai direvisi, peneliti melakukan uji coba kelompok kecil kepada 5 siswa kelas VIII C SMP Negeri 1 Tumpang. 5 siswa tersebut dipilih dengan menggunakan metode simple random sampling yang dilaksanakan oleh guru Seni Budaya yang mengajar di kelas tersebut.

Hasil dari uji coba kelompok kecil ialah siswa kurang tertarik dan bosan saat menyaksikan media pembelajaran berupa video tersebut. Siswa merasa video pembelajaran yang ditayangkan hanya itu-itu saja (wawancara oleh Adelia), siswa merasa video pembelajaran yang 
ditayangkan sudah sering dilihat (wawancara oleh Alisha), siswa merasa video pembelajaran yang ditayangkan membuat mengantuk (wawancara oleh Romi).

Sehingga, dapat disimpulkan bahwa media pembelajaran berupa video tersebut tidak menarik bagi siswa.

Revisi produk kembali dilakukan oleh peneliti dengan bantuan editor. Peneliti menambahkan bumper pada awal video. Bumper tersebut bertujuan untuk membuat siswa yang menontonnya tertarik. Bumper tersebut berisi logo Universitas Negeri Malang, serta ditambahkan musik pengiring berupa musik tarian. Sehingga siswa dapat tertarik dan akan penasaran untuk melihat video tersebut secara lengkap / sampai selesai.

Hasil revisi kedua tersebut dikonfirmasi kembali pada validator materi dan validator media. Validator materi memberi saran yaitu dalam penayangan video tersebut perlu adanya dubbing agar siswa dapat lebih tertarik dan memahami materi yang ditayangkan, serta agar siswa tidak bosan. Siswa lebih tertarik pada media pembelajaran yang merangsang lebih dari satu indera.

Saran dari validator media ialah perlu adanya penambahan musik pengiring pada bumper, serta penambahan efek pada logo Universitas Negeri Malang, sehingga siswa dapat lebih tertarik pada media pembelajaran berupa video tersebut. Para validator menyatakan bahwa dengan adanya bumper, dapat menarik siswa yang menonton video pembelajaran. Siswa harus dibuat penasaran di awal tayangan video agar siswa ingin menonton hingga selesai.

Revisi kembali dilakukan dengan mempertimbangkan saran dari para validator. Peneliti dibantu dengan editor menambahkan musik pengiring pada bumper, menambahkan juga efek bergerak logo Universitas Negeri Malang, serta menambahkan dubbing pada media pembelajaran berupa video tersebut. Perekaman dubbing dilakukan dan dibantu oleh teman peneliti dan editor.

Menit ke 0 sampai menit pertama merupakan tayangan bumper dengan gambar animasi dan musik pengiring yang menarik. Kemudian, pada menit pertama sampai kedua berisi sinopsis tari beserta dubbing.

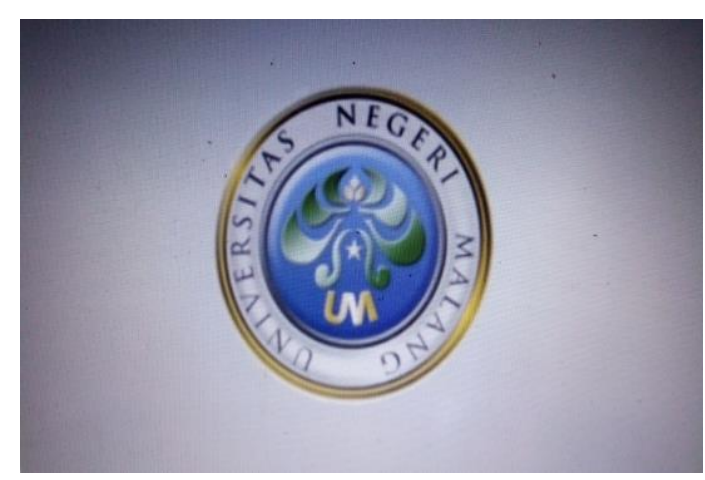

Gambar 1. Slide Bumper

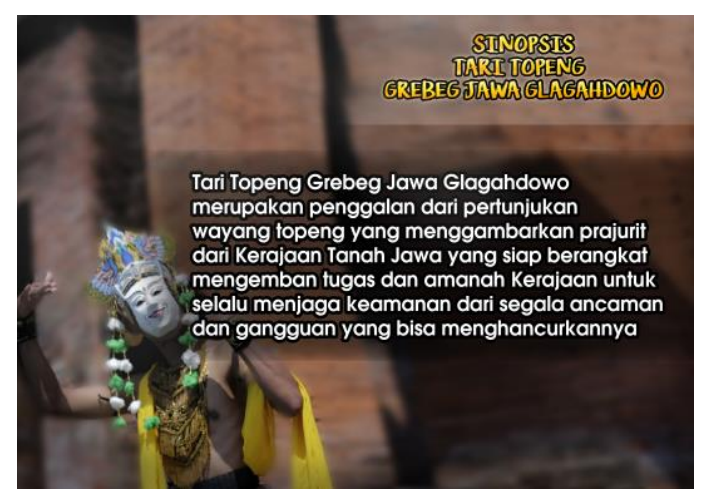

Gambar 2. Slide Sinopsis

Setelah revisi selesai dilaksanakan, peneliti sekali lagi melakukan uji coba. Namun uji coba kali ini dilaksanakan oleh seluruh siswa kelas VIII C SMP Negeri 1 Tumpang yang berjumlah 31 siswa. Pada uji coba kelompok besar juga disaksikan oleh guru Seni Budaya yang mengajar di kelas tersebut. Siswa terlihat antusias saat melihat tayangan video tersebut. Guru Seni Budaya yang mengajar di kelas tersebut juga terlihat senang saat melihat para siswa dapat belajar dengan antusias. Sehingga kemungkinan besar siswa dapat menerima materi pembelajaran dengan baik dan dapat memahami materi pembelajaran.

Ronald Mantik selaku guru Seni Budaya yang mengajar di kelas VIII C SMP Negeri 1 Tumpang menyatakan bahwa media pembelajaran yang menarik dapat memberikan dampak yang positif pada siswa. Siswa dapat lebih memahami materi pembelajaran yang ada pada video pembelajaran tersebut.

Media pembelajaran berupa video tersebut dapat menarik siswa di awal video sehingga siswa tertarik untuk melihat tayangan video sampai habis, siswa juga dapat dengan mudah memahami materi pembelajaran yang terdapat pada video tersebut. Media pembelajaran berupa 
video tersebut dapat membantu guru dalam kegiatan pembelajaran di kelas.

Saran yang diberikan oleh siswa, guru, narasumber tarian, dan para ahli validator menyatakan bahwa pentingnya point of interest pada media pembelajaran terutama video. Point of interest tersebut harus dapat menarik bagi para penonton terutama siswa pada suatu video pembelajaran. Agar siswa dapat lebih mudah memahami materi pembelajaran dan tidak bosan saat melihat tayangan video pembelajaran tersebut. Point of interest ditayangkan di awal video pembelajaran agar siswa tertarik dan ingin melihat tayangan video tersebut sampai selesai. Dengan demikian, siswa dapat menerima materi pembelajaran dengan baik serta dapat memahaminya.

\section{KESIMPULAN}

Video pembelajaran tari yang baik untuk mendukung pembelajaran tari pada siswa SMP adalah video yang memiliki point of interest pada introduksi di menit pertama dan penggalan highlight tarian di menit kedua. Sehingga, dapat disimpulkan bahwa video pembelajaran tari yang baik adalah video yang membangun rasa penasaran penontonnya pada 2 menit pertama.

\section{DAFTAR PUSTAKA}

Arsyad, A. (2014). Media Pembelajaran (1st ed.). Jakarta: PT Raja Grafindo Persada.

Khusairi, A. R. F., Zandra, R. A., \& Harini, N. (2019). Ketrampilan Memainkan Recorder Melalui Model Kooperatif Tipe Jigsaw. Promusika, 7(1), 1-10. https://doi.org/10.24821/promusika.v7i1.2 659

Rahayuningtyas, W. (2013). Pengemasan Bahan Ajar Tari Topeng Malang Pada Mata Kuliah Vokasi Tari Malang. Harmonia Journal of Arts Research and Education, 13(1), 29-36. https://doi.org/10.15294/harmonia.v13i1.2 530

Rahmawati, A. P., Pratamawati, E. W. S. D., \& Zandra, R. A. (2017). M-Learning Teori Musik Dalam Aplikasi Smartphone Android. Jurnal of Art, Design, Art Education And Culture Studies (JADECS), 2(2), 128-135.

Sasmito, L., \& Rahayu, S. (2014). Media Promosi "Ayo Nyang Posyandu " Tari Memengan di Banyuwangi, Jawa Timur (
A Media Promotion through " Ayo Nyang Posyandu " Memengan Dance in Banyuwangi, East Java ). (17), 143-150.

Sugiyono. (2015). Metode Penelitian Kuantitatif, Kualitatif, dan R\&amp;D (22nd ed.). Bandung: Alfabeta.

Zandra, R A, Wido, S., \& Desta, K. (2018). Mimikri Dan Hibrida Dalam Lagu "Blauran Wayah Sore" Orkes Keroncong Aneka Warna. Seminar Antar Bangsa: Seni Budaya Dan Desain-STANSA, 301307.

Zandra, Rully Aprilia. (2014). Sejarah Musik Keroncong di Surabaya. 12(1), 74-111.

Zandra, Rully Aprilia. (2019). Keroncong Gaya Keempat (Kajian Bentuk Dan Gaya Penyajian). Journal of Art, Design, Art Education And Culture Studies (JADECS), 4(1), 39-47. 